\title{
$\mathrm{JN}$

\section{EFFECT OF RECREATIONAL TRAIL TRAFFIC LEVEL ON EASTERN RED-BACKED SALAMANDER (PLETHODON CINEREUS) RELATIVE ABUNDANCE}

\author{
ANTHONY C. BURGER ${ }^{1}$, BRETT W. MARLOWE ${ }^{1}$, ELIZABETH P. TRISTANO ${ }^{1,2}$, GEOF- \\ FREY R. SMITH ${ }^{1,3}$, AND JESSICA E. RETTIG ${ }^{1}$ \\ ${ }^{1}$ Department of Biology, Denison University, Granville, OH 43023 \\ 2Present Address: Department of Zoology, Southern Illinois University, Carbondale, \\ IL 62901 \\ ${ }^{3}$ Author for Correspondence: smithg@denison.edu
}

\begin{abstract}
The effects of roads and trails on terrestrial salamanders, primarily plethodontids, can be important. The abundance of terrestrial salamanders often increases with distance from roads. Less is known about the effects of recreational or hiking trails on terrestrial salamanders than is known about the effects of roads. We explored how low and high traffic trails in a suburban biological reserve affect the relative abundance of Eastern Red-backed Salamanders (Plethodon cinereus). We found more salamanders under cover objects next to low traffic trails compared to either high traffic trails or wooded areas without trails. At wooded sites, we found only striped morphs whereas at high traffic sites we found only unstriped morphs. Low traffic sites included a range of color morph frequencies. The proportion of females found in each site did not differ, nor did the mean size of the salamanders. Our results suggest that the impact of recreational walking trails needs to be examined more closely to see how and why the distributions of $P$. cinereus, and potentially other woodland salamanders, are affected and what trail characteristics are important in driving the apparent effects. Such information will contribute to the design and maintenance of walking trails in natural areas that minimize effects on terrestrial salamanders, and likely other organisms.
\end{abstract}

\section{INTRODUCTION}

Natural areas, including protected areas and biological reserves, are often criss-crossed with roads and/or trails (Wimpey and Marion, 2010). Use of such areas for recreation is likely to increase as the density of housing near many protected areas is expected to increase in the future (Hansen et al., 2014), thus it might be expected that the use of roads and trails in these areas is also likely to increase.

The effects of roads and trails on terrestrial salamanders, primarily plethodontids, can be important. Roads, especially larger ones and those with more traffic, can restrict the movement of plethodontid salamanders (e.g., Gibbs, 1998; deMaynadier and Hunter, 2000; Marsh et al., 2005, 2008; Marsh, 2007), and edge effects on salamanders appear to be more important along larger roads (Marsh, 2007). In many cases the abundance of terrestrial salamanders increases with distance from roads (de Maynadier and Hunter, 2000; Marsh and Beckman, 2004; Semlitsch et al., 2007). Less is known about the effects of recreational or hiking trails on terrestrial salamanders compared to road effects. Fleming et al. (2011) examined the effects of distance from maintained and unmaintained, low traffic trails on the observed abundance of Eastern Red-backed Salamanders (Plethodon cinereus). They found that the number of salamanders, as well as the number of striped morph salamanders in particular, was higher nearer to maintained trails, and distance to an unmaintained trail had no effect. Davis (2007) found more terrestrial salamanders (mostly $P$. glutinosus) near walking trails.

We explored how low and high traffic trails in a suburban biological reserve might impact the relative abundance of $P$. cinereus. Based on the research cited above, we predicted that the lowest observed abundance of salamanders would be found along the high traffic trails and abundance would be greatest along low traffic trails.

\section{MATERIALS AND METHODS}

Our study took place at the Denison University Biological Reserve (DUBR), Granville, Licking Co., Ohio $\left(40^{\circ} 05^{\prime} 07.32^{\prime \prime} \mathrm{N}, 82^{\circ} 30^{\prime} 33.92^{\prime \prime} \mathrm{W}\right)$ during April 2012. Three habitat types were identified: high traffic trail, low traffic trail, and an interior woodland habitat (Figure 1). Trails and the interior woodland habitats were embedded 
Table 1. Mean ( \pm 1 S.E.) number of cover objects searched, number of Eastern Red-backed Salamanders (Plethodon cinereus), number of salamanders per cover object searched, proportion of striped morph, proportion of females, and salamander SVL for wooded, low traffic trail, and high traffic trail sites at the Denison University Biological Reserve, Granville, Licking Co., Ohio, USA. N is given in parentheses. Means sharing a letter are not significantly different based on Wilcoxon pairwise tests.

\begin{tabular}{lccc}
\hline & Wooded Site & Low Traffic Site & High Traffic Site \\
\hline \# Cover Objects & $5.26 \pm 0.29^{\mathrm{a}}(10)$ & $8.00 \pm 0.44^{\mathrm{b}}(10)$ & $8.56 \pm 0.67^{\mathrm{b}}(10)$ \\
\# P. cinereus & $0.066 \pm 0.044^{\mathrm{a}}(10)$ & $0.897 \pm 0.30^{\mathrm{b}}(10)$ & $0.132 \pm 0.07^{\mathrm{a}}(10)$ \\
\# P. cinereus/cover object & $0.013 \pm 0.009^{\mathrm{a}}(10)$ & $0.107 \pm 0.034^{\mathrm{b}}(10)$ & $0.020 \pm 0.012^{\mathrm{a}}(10)$ \\
Proportion of Striped Morph & $1^{\mathrm{a}}(2)$ & $0.63 \pm 0.14^{\mathrm{a}}(8)$ & $0^{\mathrm{b}}(3)$ \\
Proportion of Females & $0.50 \pm 0.5^{\mathrm{a}}(2)$ & $0.32 \pm 0.10^{\mathrm{a}}(8)$ & $0.50 \pm 0.29^{\mathrm{a}}(3)$ \\
SVL (cm) & $3.75 \pm 0.85^{\mathrm{a}}(2)$ & $3.80 \pm 0.28^{\mathrm{a}}(8)$ & $3.38 \pm 0.53^{\mathrm{a}}(3)$ \\
\hline
\end{tabular}

in a mixed mesophytic forest (dominant species = Sugar Maple, Acer saccharum). The high traffic trail is in close proximity to a field station and the main entrance and parking lot for the DUBR, and thus experiences a high volume of pedestrian activity. The low traffic trail is located at some distance $(700 \mathrm{~m})$ from the entrance to the DUBR and experiences lower levels of foot traffic compared to the high traffic trail. The interior wood habitat is located approximately $20 \mathrm{~m}$ away from any trails and well away from the entrance of the DUBR ( $>1 \mathrm{~km})$. While we did not quantitatively assess pedestrian traffic at each site, our qualitative observations of visitation and trail use patterns at the DUBR over several years suggest that pedestrian traffic is much higher closer to the main parking lot and within the Alrutz section of the DUBR where the high traffic site was located relative to the Norpell section where the low traffic and interior wood habitat sites were located (see Figure 1). In addition, further evidence of higher pedestrian traffic at our high traffic site is provided by the higher amount of trail wear found at this site compared to the low traffic trail site.

For each habitat type, we established ten $3 \mathrm{~m} \times 3 \mathrm{~m}$

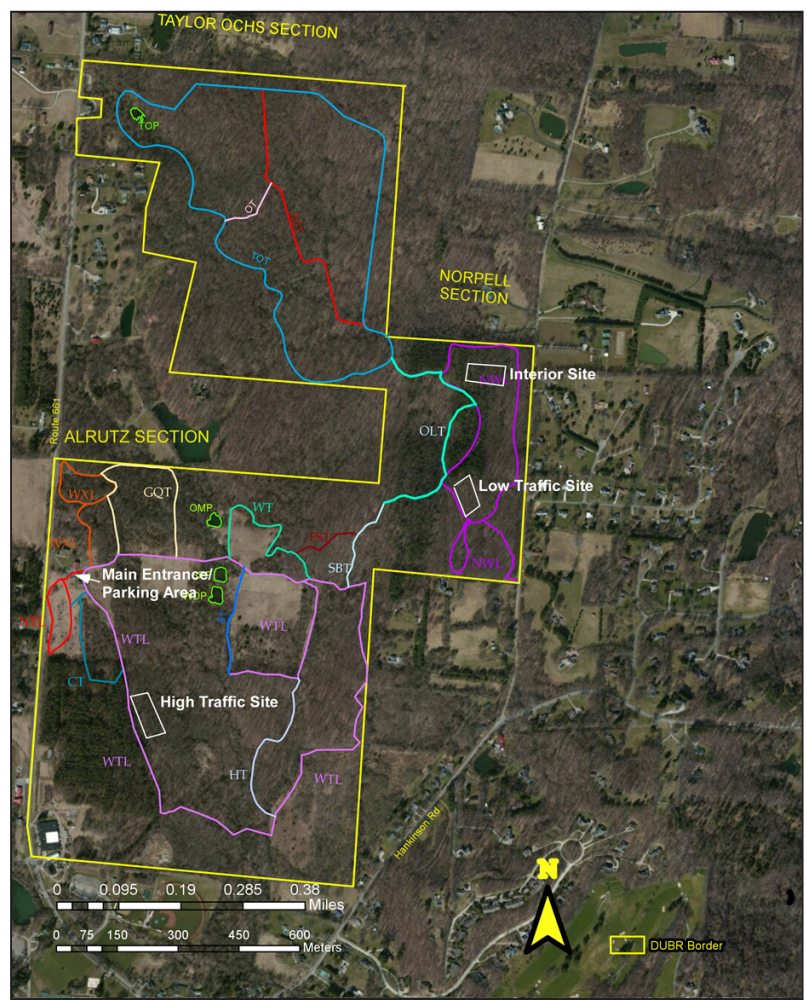

Figure 1. Location of the three study sites within the Denison University Biological Reserve (DUBR), Granville, Licking County, Ohio.Trail and DUBR map created by Rima Jurjus. plots. For trail sites, these plots were placed immediately adjacent to the trail. Each plot was sampled on 4, 6, and 15 April 2012, for a total of three surveys per plot. This sampling period corresponds with a period of higher numbers of $P$. cinereus under cover objects in this general area (Grasser and Smith, 2014). For each sampling date and plot, we recorded the number of natural cover objects (e.g., primarily large downed branches or logs and, more rarely, rocks) searched and the number of salamanders present, as well as the snout-vent length (to nearest $\mathrm{mm}$ ), color morph (striped or unstriped), and sex of each salamander based on external traits given in Petranka (1998). For analyses, we used the mean for the three sampling dates for each plot. Due to likely violations of the assumptions of parametric analyses, we used non-parametric Wilcoxon/KruskalWallis Tests to compare the number of cover objects searched, the number of salamanders observed, number of salamanders observed per cover object searched, the mean length of salamanders, the proportion of striped morphs, and the proportion of females among the different site types. Significant tests were followed with Wilcoxon tests among all pairwise comparisons to determine which sites differed. We also used linear regression between the number of cover objects in a plot and number of salamanders observed, mean salamander size, proportion of striped morph salamanders, and proportion of females for each plot.

\section{RESULTS}

The number of cover objects searched was lowest in the wooded plots compared to the low and high traffic trail plots (Table $1 ; c_{2}^{2}=16.08, P=0.0003$ ). The number of salamanders observed in a plot was not significantly related to the number of cover objects searched $(\mathrm{N}=30$, $\left.r^{2}=0.057, P=0.20\right)$. The mean length of salamanders was not related to the number of cover objects searched $\left(\mathrm{N}=13, \mathrm{r}^{2}=0.02, \mathrm{P}=0.61\right)$. The number of cover objects searched did not affect the proportion of striped morph salamanders $\left(\mathrm{N}=13, \mathrm{r}^{2}=0.0013, \mathrm{P}=0.90\right)$ or the proportion of female salamanders $\left(N=13, r^{2}=\right.$ $0.0026, P=0.87$ ).

The number of salamanders was highest in the low traffic trail plots compared to the high traffic trail and wooded plots (Table $1 ; X_{2}{ }_{2}=10.52, P=0.0052$ ). The number of salamanders per cover object searched was also highest in the low traffic trail plots compared to the high traffic and wooded plots (Table $1 ; X^{2}{ }_{2}=8.33, \mathrm{P}=$ $0.016)$. The proportion of striped morph salamanders differed among sites (Table $1 ; X_{2}^{2}=6.94, P=0.03$ ). In wooded plots, we detected only striped morph salamanders, whereas in high traffic edge plots we found no striped morph salamanders. The proportion of striped morph salamanders ranged from $0-1$ in the low traffic plots. There was no difference in the proportion of 
striped morph salamanders in the low traffic and wooded plots. The proportion of striped morph salamanders was not related to the number of salamanders observed in a plot $\left(\mathrm{N}=13, \mathrm{r}^{2}=0.0026, \mathrm{P}=0.87\right)$. The proportion of females did not differ among sites (Table $1 ; X_{2}^{2}=0.47, P$ $=0.79$ ). The proportion of female salamanders was not related to the number of salamanders observed in a plot $\left(\mathrm{N}=13, \mathrm{r}^{2}=0.056, \mathrm{P}=0.44\right)$. Mean salamander size did not differ among the different types of sites (Table $1 ; X_{2}^{2}$ $=0.26, P=0.88)$. Salamander length was not related to the number of salamanders observed in a plot $(N=13$, $\left.r^{2}=0.0001, P=0.97\right)$.

\section{DISCUSSION}

Our results demonstrate that the observed abundance of $P$. cinereus under natural cover objects was affected by the presence of trails, as well as the relative amount of pedestrian traffic. We observed significantly more salamanders under cover objects next to low traffic trails compared to either high traffic trails or wooded areas without trails, suggesting some level of trail construction or use may increase the relative abundance of salamanders. Our results agree with the observations of Fleming et al. (2011) from another low traffic trail in the Denison University Biological Reserve who found more $P$. cinereus nearer to the trail than in wooded areas. Davis (2007) argued that the higher number of salamanders that he observed near trails was because of an increase in suitable microhabitats closer to the trails due to an increase in logs near trails. Logs may be more numerous near our trails because downed trees that fall across trails are removed from the trails and the cut logs left in place near the trails. In the interior sites, fallen trees are not cut and thus there are fewer potential cover objects. The difference in the number of cover objects may partially explain our results, although it does not appear able to explain all of the differences between sites. For example, both low and high traffic trail plots had more potential cover objects (e.g., logs and downed branches) than the wooded plots, but the low traffic plots had a higher number of salamanders observed per cover object than the high traffic plots. This result suggests that additional factors are likely responsible for the difference in observed salamander abundance among the different trails, such as increased disturbance due to pedestrian traffic affecting salamander abundance near high traffic trails. For example, Garner et al. (2008) found fewer frogs along trails with greater human activity or disturbance. Higher traffic sites may also have different abiotic conditions than low traffic sites. Recreational trails have been associated with increased non-native plant species richness and cover (e.g., Wells et al., 2012), and decreased plant species richness and increased soil compaction (e.g., Crisfield et al., 2012). Thus, there may be an intermediate level of trail use that provides a combination of environmental conditions that is more optimal for salamander abundance (i.e., a "Goldilocks" effect).

We also found that the frequency of the two morphs of $P$. cinereus, striped and unstriped, differed among sites. At wooded sites, we found only striped morphs whereas at high traffic sites we found only unstriped morphs. Low traffic trail plots had a range of morph frequencies. Fleming et al. (2011) found fewer striped morph salamanders as the distance to a low traffic, maintained trail increased. These results suggest that the two color morphs may respond to trail use, or the associated environmental conditions, differentially. To some extent, the fact that the two color morphs in $P$. cinereus might respond differentially to trails should not be that surprising. Previous research has shown that the striped and unstriped morphs differ physiologically and ecologically. For example, these two color morphs have been shown to differ in maintenance metabolic rate (Petruzzi et al., 2006), thermal niche (Angleberger and Chinnici, 1975; Lotter and Scott, 1977; Petruzzi et al., 2006; Anthony et al., 2008), stress response (Davis and Milanovich, 2010), activity period (Anthony et al., 2008), rehydration rate (Smith et al., 2015), and diet (Anthony et al., 2008). These differences appear to have consequences for the distribution of these two color morphs on a broader geographic scale (e.g., with latitude, longitude, elevation; Greer, 1973; Gibbs and Karraker, 2006). Our results, and those of Fleming et al. (2011) suggest that the distribution of the two color morphs may also vary at a smaller scale with respect to recreation trail use and distribution. The underlying reason for this difference is not known, but merits additional research. We suspect it may be related to differences in the thermal and hydric niches of these two morphs, but further exploration of the ecology of salamanders near and far from trails of varying pedestrian traffic are needed to draw any conclusion.

In conclusion, differences in abundance and frequency of two morphs of $P$. cinereus were associated with the presence of recreational trails in a biological reserve, and their relative use by pedestrians. However, no differences among sites were detected in either sex ratios or body sizes of adults. Our results, along with those of Fleming et al. (2011) and Davis (2007), suggest that the impact of recreational walking trails is significant enough to merit further examination to see how and, perhaps more importantly, why the distributions of $P$. cinereus, and possibly other woodland salamanders, are affected and what characteristics of such trails might drive the apparent effects. Such information will be useful in the design and maintenance of walking trails in natural areas that minimize their effects on terrestrial salamanders, and likely other organisms as well.

Acknowledgements - This research was conducted with the approval of the Denison University IACUC (\#10-002). We thank two anonymous reviewers for their helpful comments on this manuscript.

\section{LITERATURE CITED}

Angleberger, M.A.P., and J.P. Chinnici. 1975. Dimorphism in the Red-backed Salamander Plethodon cinereus (Green) at Mountain Lake, Virginia. Virginia Journal of Science 26: 153-158.

Anthony, C.D., M.D. Venesky, and C.-A.M. Hickerson. 2008. Ecological separation in a polymorphic terrestrial salamander. Journal of Animal Ecology 77: 646-653.

Crisfield, V.E., S.E. Macdonald, and A.J. Gould. 2012. Effects of recreational traffic on alpine plant communities in the Northern Canadian Rockies. Arctic, Antarctic, and Alpine Research 44: 277-287.

Davis, A.K. 2007. Walking trails in a native preserve alter terrestrial salamander distributions. Natural Areas Journal 27: 385-389.

Davis, A.K., and J.R.M. Milanovich. 2010. Lead-phase and red-stripe color morphs of red-backed salamanders Plethodon cinereus differ in hematological stress indices: A consequence of differential predation pressure? Current Zoology 56: 238-243.

deMaynadier, P.G., and M.L. Hunter Jr. 2000. Road effects 
on amphibian movements in a forested landscape. Natural Areas Journal 20: 56-65.

Fleming, M.M., L.B. Mills, J.K. Russell, G.R. Smith, and J.E. Rettig. 2011. Effects of trails on Eastern Redback Salamander (Plethodon cinereus Green). Herpetology Notes 4: 229-232.

Garner, T.W.J., D. Nishimura, J. Antwi, and N. Oliver. 2008. Human disturbance influences behavior and local density of juvenile frogs. Ethology 114: 10061013.

Gibbs, J.P. 1998. Amphibian movements in response to forest edges, roads, and streambeds in southern New England. Journal of Wildlife Management 62: 584-589.

Gibbs, J.P., and N.E. Karraker. 2006. Effects of warming conditions in eastern North American forests on Red-backed Salamander morphology. Conservation Biology 20: 913-917.

Grasser, C.N., and G.R. Smith. 2014. Effects of cover board age, season, and habitat on the observed abundance of Eastern Red-backed Salamanders (Plethodon cinereus). Journal of North American Herpetology 2014: 53-58.

Greer, A.E. Jr. 1973. Adaptive significance of the color phases of the Red-backed salamander. Yearbook of the American Philosophical Society 973: 308-309.

Hansen, A.J., N. Piekielek, C. Davis, J. Haas, D.M. Theobald, J.E. Gross, W.B. Monahan, T. Olliff, and S.W. Running. 2014. Exposure of U.S. National Parks to land use and climatic change 1900-2100. Ecological Applications 24: 484-502.

Lotter, F., and N.J. Scott Jr. 1977. Correlation between climate and distribution of the color morphs of the salamander Plethodon cinereus. Copeia 1977: 681690.

Marsh, D.M. 2007. Edge effects of gated and ungated roads on terrestrial salamanders. Journal of Wildlife
Management 71: 389-394.

Marsh, D.M. and N.G. Beckman. 2004. Effects of forests roads on the abundance and activity of terrestrial salamanders. Ecological Applications 14:1882-1891.

Marsh, D.M., G.S. Milam, N. P. Gorham, and N.G. Beckman. 2005. Forest roads as partial barriers to terrestrial salamander movement. Conservation Biology 19: 2004-2008.

Marsh, D.M., R.B. Page, T.J. Hanlon, R. Corritone, E.C. Little, D.E. Seifert, and P.R. Cabe. 2008. Effects of roads on patterns of genetic differentiation in red-backed salamanders, Plethodon cinereus. Conservation Genetics 9: 603-613.

Petranka, J.W. 1998. Salamanders of the United States and Canada. Smithsonian Institution Press, Washington.

Petruzzi, E.E., P.H. Niewiarowski, and F.B.-G. Moore. 2006. The role of thermal niche selection in maintenance of a colour polymorphism in redback salamanders (Plethodon cinereus). Frontiers in Zoology 3:10.

Semlitsch, R.D., T.J. Ryan, K. Hamed, M. Chatfield, B. Drehman, N. Pekarek, M. Spath, and A. Watland. 2007. Salamander abundance along road edges and within abandoned logging roads in Appalachian forests. Conservation Biology 21: 159-167.

Smith, G.R., T. Johnson, and W.O. Smith. 2015. Effects of colour morph and season on the dehydration and rehydration rate of Plethodon cinereus. AmphibiaReptilia 36: 170-174.

Wells, F.H., W.K. Lauenroth, and J.B. Bradford. 2012. Recreational trails as corridors for alien plants in the Rocky Mountains, USA. Western North American Naturalist 72: 507-533.

Wimpey, J.F., and J.L. Marion. 2010. The influence of use, environmental and managerial factors on the width of recreational trails. Journal of Environmental Management 91: 2028-2037. 